\title{
Integrated Student Leadership Development: A Qualitative Case Study on Building the Intercultural Competence of First-Year Honors Students
}

\begin{abstract}
Authors' Note: The authors wish to express their gratitude to Ms. Elsina Hagan whose editorial support contributed to revisions reflected in this article.
\end{abstract}

\begin{abstract}
There are many studies regarding the value of gaining cultural awareness, but limited empirical evidence has been shared on programs that use integrated learning and capacity building interventions to specifically build cultural competence in aspiring undergraduate leaders. This qualitative case study examined the effects of interventions designed to build intercultural competence in first-year honors students participating in a leadership development program using co-curricular activities, undergraduate research, and a short-term education abroad. Data collected from two cohorts who completed the first year of the program revealed students' perceptions of their short-term education abroad experience's impact on their intercultural competence and leadership development. The study demonstrates the value of integrated leadership and intercultural competence development among undergraduate students.
\end{abstract}

\section{Introduction}

Developing students' intercultural competence has become a fundamental outcome for undergraduate leadership programs (Komives, Dugan, Own, Slack, \& Wagner, 2006; Niehaus, O'Rourke, \& Ostick, 2012; Seemiller, 2013). Leadership educators acknowledge that twentyfirst century leaders will encounter unprecedented complexity in an ever-interconnected world (Sowcik, Andenoro, McNutt, \& Murphy, 2015). Consequently, we strive to provide responsive, integrated leadership development curricula and experiences necessary for preparing future leaders. One critique of student leadership development programs is the often-disjointed approach to what could be a more holistic, seamless educational experience (Haber-Curran \& Owen, 2013). In response to the desire to develop more holistic educational experiences, educators have developed and advocated for the integration of curricular and co-curricular learning experiences (Kuh, 2008). Examples of these pedagogical strategies, identified as HighImpact Educational Practices, include first-year seminars, undergraduate research, and diversity and global learning. These practices support student academic success and are common elements in leadership education (Ganz \& Lin, 2011; Jenkins, 2013; Wilson, 2015).

This article discusses research on one such program offered at a public comprehensive four-year university located in the southeast region of the United States. Specifically, the leadership development program was created to provide selected high achieving first-year students the opportunity to develop leadership skills through curricular and co-curricular activities that connect undergraduate research, cultural awareness, and civic engagement through an education abroad experience to help participants become more globally competent citizens. The purpose of this study was to examine the ways in which students in two cohorts of this 
program made meaning of these pedagogical approaches during a short-term education abroad. Students in this program participated in various high-impact activities throughout the academic year, and during the education abroad at the end of their first year, they had the opportunity to reflect on how these preparatory experiences helped them become more interculturally competent.

\section{Experiences that Lead to Intercultural Competence}

Education abroad is a central experience that promotes understanding of different cultures. The number of students receiving education outside of their home countries has risen dramatically through the use of short-term education abroad programs (Jackson, 2015). Research has shown that education abroad experiences, even short-term, can help build intercultural competency (e.g., Caffrey, Neander, Markle, \& Stewart, 2005; Ferranto, 2015; Smith, McAuliffe, \& Rippard, 2014), especially if those experiences include service-learning (Bentley \& Ellison, 2007; Walling, Eriksson, Meese, Ciovica, Gorton, \& Foy 2006) and working cooperatively with culturally diverse individuals (Jackson, 2015; Wells, 2000). For example, students report being transformed by learning experiences abroad (Bentley \& Ellison, 2007; Ferranto, 2015; Miller-Perrin \& Thompson, 2014; Smith et al., 2014) as well as positive views toward the host country and their residents (Ferranto, 2015; Kartoshkina, 2015). However, sometimes these experiences lead students to derogate their own country's culture (Kartoshkina, 2015; Smith et al., 2014; Walling et al., 2006) and experience feelings of guilt, often about the affluence of their own country relative to the host country (Bentley \& Ellison, 2007; Ferranto, 2015).

Other academic experiences can help foster intercultural competence, especially when paired with an education abroad experience. For example, undergraduate research is a key development component for success in higher education (Kuh, 2008). Benefits of undergraduate research include improved student learning through developing a faculty mentorship relationship; increased student retention; more students pursuing graduate-level education; improved career preparation; improved skills that support critical thinking, creativity, and problem-solving; enhanced research skills; and an enhanced culture of innovation (Council on Undergraduate Research, n.d.).

Zimmerman (2015) noted that cultural understanding forms the foundation for the global leadership skillset required for today's leaders. Miles (2003) suggests a constructivist instructional approach-learning by doing and experience-as an intervention strategy. Constructivist learning, such as role-playing, shared learning, and small-group discussion, creates an interdisciplinary framework and allows students to holistically develop intercultural competencies through coursework, research, experiences, and reflections (Devine, Green, \& McDowell, 2010). Braskamp and Engberg (2011) argue that experiences outside the formal classroom setting influence cross-cultural awareness, especially those where students interact with peers who are unlike themselves and involve students' processing and reflecting upon these new encounters and experiences. Additionally, the literature indicates learners who participate in course offerings, co-curricular activities, education abroad opportunities, diverse 
learning communities, and civic engagement with the intent of raising consciousness around multiculturalism will experience behavioral and cognitive changes in their intercultural competence (Morris \& McClure, 2011). For the purpose of this study, intercultural competence is defined by Dr. Milton J. Bennett's broad reference to the ability to appreciate differences through the learned and shared patterns of beliefs, behaviors, and values of people interacting from different cultural backgrounds (Bennett, 1998, 2009).

In sum, the existing research suggests benefits related to high-impact practices such as education abroad, undergraduate research, and constructivist educational approaches. However, there is insufficient research on the impact of integrated experiences for building intercultural competence among first-year students in particular. Furthermore, there is sparse research on education abroad experiences during students' first year of college that encourage building these specific leadership skill sets (Olson \& Lalley, 2012). The program featured in this study was developed in response to an institutional Quality Enhancement Plan (QEP) focused on enhancing global learning of students, faculty, and staff. One initiative created was a three-year leadership development program that was informed by available literature addressing leadership and intercultural competence development along with enhancing skills that promote academic success. As facilitators and observers of this innovative student leadership development offering, the authors will present an overview of the program, an analysis of the data, and recommendations for practice and future research, including suggestions for program development.

\section{Context}

This study was conducted at a public comprehensive four-year university located in the southeast region of the United States. During the time of this study, the program was conducted over a three-year period starting in the students' first year. The first semester included a required 3-credit hour first-year seminar focused on globalization and weekly meetings that continued over the course of the program's three years. Students participated in leadership development workshops on domestic diversity and international worldview. The intent was to develop selfidentified prospective student leaders who would be equipped with leadership skills for entry into a global society. The program fostered interactions among the students and facilitators that encouraged open dialogue and promoted critical thinking, collective learning, and meaning making on issues of diversity and inclusion. Paige (1993) noted that education for intercultural experiences can be challenging for some participants, and there is a need to have pedagogy that is different from traditional instructional practices. Research also suggests that these forms of interactions and connections with others enhance social networking and academic development (Belford, 2017), and "students learn more by putting more energy and time into the learning process" (Eldaba, 2016 p. 172). Participants were recruited from admitted first-year students with a 3.5 or higher high school GPA and a score of 1150 or higher on the SAT or 25 or higher on the ACT. Previous leadership experience was preferred but not required.

The program incorporates the components that research has shown improve cultural competence, including constructivist learning strategies (Miles, 2003), interactions with diverse 
others (Wells, 2000), a short-term educational abroad experience (Smith et al., 2014), and opportunities for self and group reflection about the new knowledge gained from exposure to the experiences (Braskamp \& Engberg, 2011; Jackson, 2015). The purpose of these components was to foster the following learning outcome domains that support intercultural competence:

- Consciousness of Self - Students will gain an understanding of leadership attributes and global perspectives that will facilitate their own personal and professional growth as aspiring global leaders.

- Communication - Students will enhance oral, written, and interpersonal communication skills.

- Diversity - Students will be introduced to other cultural frameworks that encourage curiosity, empathy, and respect.

- Intercultural Competence Development - Students will gain an understanding of their own current level of intercultural sensitivity that promotes multicultural awareness.

- Teamwork - Students will learn about effective team development and demonstrate collaborative behaviors that support group dynamics and accountability.

- Civic Engagement and Citizenship - Students will participate in civic engagement activities that promote global citizenship and leadership attributes.

Combined, these learning outcomes support the development of the skills, values, and behaviors necessary for intercultural competence.

\section{Methodology}

This study uses a qualitative case study as the primary form of collecting and synthesizing data. Data for this study were collected through qualitative design strategies (group debriefings, one-on-one interviews discussing cultural assessment results, and responses to prompted reflective questions). Yin (2009) defined case study as a research method used to "understand complex social phenomena that allows investigators to retain the holistic and meaningful characteristics of real-life events" (p. 4). Utilizing a qualitative case study design allowed the researchers to delve deeper into conversations around sensitive issues regarding the students' development of cultural awareness as they participated in the interventions provided by the program.

Participants for this study consisted of two cohorts of high-achieving students: Cohort 1 (AY2012-2013) and Cohort 2 (AY2013-2014). There were 27 students in Cohort 1 with 19 participating in the education abroad experience to Brazil. Cohort 2 consisted of 26 students, 
with 17 participating in the same excursion. The university is a Predominately White Institution (PWI). Given the overall demographics of the university's student population, the majority of the participants in each cohort were White/Caucasian, with more female than male participants. Additionally, there was a very low number of students of color. Some students may have opted out of the education abroad due to finances and/or employment responsibilities.

Interventions Designed to Promote Intercultural Competence. Several curricular and co-curricular activities were incorporated to promote intercultural competence. In their first semester, students enrolled in a themed first-year seminar entitled "Tomorrow's World Today." Students in this course were exposed to the Seven Revolutions (population, resource management, technology, knowledge/information, economic integration, conflict/security, and governance), which are considered key drivers of global change over the next 25 years (Center for Strategic and International Studies, 2015). Students completed assignments related to the Seven Revolutions and other global issues as well as assignments designed to promote academic success (e.g., learning strategies, time management, effective study habits).

Co-curricular experiences. Additionally, several workshops, presentations, and activities were developed to help the students become more culturally aware. A variety of methods were used (e.g., films, panel presentations, interactive games, reflective exercises) in order to be engaging and sensitive to students' developmental levels (Hammer, Bennett, \& Wiseman, 2003). Furthermore, activities to promote team cohesion included social outings such as sporting events, volunteer services, visits to museums, and lunch/dinner engagements. Belford (2017) posits that "social interaction and friendship development play a significant role in the adjustment process....in supporting students' well-being..." (p. 515). Structured extracurricular activities can have significant effects on leadership and academic excellence (Mahoney \& Cairns, 1997).

Undergraduate research. The undergraduate research project was built upon the Seven Revolutions framework (Center for Strategic and International Studies, 2015). The students rank-ordered their interest in the seven components and were then placed in teams of 3-4 assigned to their preferred revolution issue. Each team was responsible for designing a survey about some aspect of their assigned revolution. Each group was asked to limit the number of questions to about 10-15 items because all seven surveys were combined into one comprehensive survey on the Seven Revolutions and administered online to a sample of undergraduate students at universities in Brazil and in the United States.

In both cohorts, students learned research fundamentals in their first semester (e.g., finding scholarly sources at the library, constructing valid survey items, writing an empirical research report). However, each cohort had varying levels of interaction with their peers in Brazil when working on the research project, particularly in developing the survey instrument. Cohort 1 created the survey entirely on their own; the students in Brazil were not involved in the design but were asked to administer the assessment on their campus. The problem with this approach was that some of the questions designed by students in the U.S. did not necessarily make sense or translate well to a Brazilian 
context. Therefore, Cohort 2 collaborated from the beginning with the Brazilian students, who also were placed into seven teams corresponding to each of the Seven Revolutions. The corresponding teams were instructed to work together through Skype, Facebook groups, emails, etc., to come up with a common theme around their Revolution and construct survey questions accordingly.

Education abroad. At the end of the first year, students in each cohort traveled to Salvador, Brazil to participate in a short-term education abroad experience. Cohort 1 spent 10 days in Brazil and engaged in several intensive curricular and co-curricular cultural activities while on their trip that integrated the Seven Revolutions curriculum originally in the participant's first-year seminar. These interventions and reflective debriefings included: a guided tour of the city; a visit to the Odebrecht Foundation, a global company with a number of community outreach programs; service-learning at a daycare in an indigent fishing village; a viewing of the Folkloric Ballet; a tour of a petrochemical complex; a visit to a public health improvement project; and a cultural lecture from a professor at the Brazilian institute.

Cohort 2 spent 15 days in Brazil and participated in the same activities as Cohort 1 with a few changes. Most notably, Cohort 2 spent one week in homestays with families of host university's students, whereas Cohort 1 did not participate in homestays. As a result, there was more unstructured time for the students in Cohort 2, predominantly with their host families on the first weekend and in the evenings but also again on the last full day. In addition, Cohort 2 attended two lectures on culture from the same professor, who previously spoke with Cohort 1 , and two Portuguese language lessons. Cohort 2 also had more extensive time with the students with whom they collaborated on the research project: one full day of discussing the research project and several social events throughout the trip.

Intercultural Competency Assessment Instrument. An intercultural competency assessment instrument was used to inform the design of the program. Although the Developmental Model of Intercultural Sensitivity's (DMIS) theoretical framework and the related Intercultural Developmental Inventory (IDI) assessment were not directly used for data collection purposes for this study, both were valuable to enlightening facilitators about the participants' current level of thinking around cultural differences. The DMIS is used to explain how people or groups tend to think and feel about cultural difference and provides a structure for understanding how people experience cultural difference through a developmental continuum (Bennett, 1986). The first three levels are within the ethnocentric stage, meaning one's own culture is the only basis for defining reality and making judgments of others, and are (1) denial, individuals see their own culture as their central existence, and there is a disinterest in cultural difference; (2) defense, individuals take a dualistic thinking approach of "us versus them" and see their own culture, or an adopted culture, as superior and the other inferior; and (3) minimization, individuals acknowledge surface differences, such as food, customs, and clothing, but only focus on similarities among cultures, masking a deeper understanding of cultural differences (Bennett, 1998; Hammer et al., 2003). The second stage is ethnorelative, meaning one's own culture is experienced in the context of other cultures, including the ability to adapt judgments and behavior to many different settings without considering one's own culture as 
central to others. The next three levels within this stage and within the DMIS continuum are: (4) acceptance, individuals' own culture is experienced as just one of a number of equally complex worldviews; (5) adaptation, individuals are able to expand their own worldviews that yields perceptions and behaviors appropriate to that culture; and (6) integration, individuals have the ability to move in and out of different cultural worldviews seamlessly (Hammer et al., 2003).

The IDI is a theory-based instrument that measures the first five stages of the DMIS (Denial, Defense, Minimization, Acceptance, and Adaptation) from participants' responses to 50 Likert-type scale questions. The results show how individuals and groups perceive their intercultural orientation level in comparison to where they actually fall on the IDI continuum, indicating the level in which one can recognize and identify cultural development opportunities. For this study, the IDI instrument was used as a diagnostic instrument in the form of a pre-test process at the beginning of the leadership development program, in order to gain practical insights for designing and implementing appropriate programs based on students' level of learning around culture differences. A certified IDI assessor shared the IDI group results with both cohorts by way of a workshop and shared individual results in one-on-one confidential interview sessions. Based on IDI results on both cohorts' level of understanding cultural differences and multi-cultural awareness, the appropriate curriculum and co-curricular activities were developed and implemented.

\section{Data Collection and Analysis}

Qualitative data was collected from the two cohorts through focus groups and reflective essays. The interviews were conducted with specific questions around the development of intercultural competence and the impact the interventions had on the participants' development of cultural awareness. Audio recorders were used to capture conversations from meetings, interviews, and debrief sessions. The field notes supported data analysis through triangulation. Additionally, data were collected by researchers embedded in the program as well as those who worked closely with the unit and therefore were highly familiar with the program and its students. This proximal association and prolonged engagement of the researchers to the phenomena being explored coupled with the duration of the data collection via multiple methods supports trustworthiness of the data (Lincoln \& Guba, 1985).

Onsite Group Debriefings in Brazil. During the Brazil trip, the students and chaperones came together for several group debriefings to allow students the chance to process daily events to which they were exposed during the education abroad excursions. The debriefings were semi-structured, with the facilitators asking students questions, including:

1. "What were your expectations for going to Brazil? Were they met? Share a brief statement about the experience."

2. "Was it challenging to interact and communicate with the local people? Why? Give an example of an encounter." 
3. "During your visit which event on the itinerary intimidated or caused anxiety for you? Why? Give an example."

4. "What was your biggest 'culture shock' moment? Share the moment."

5. "What learning opportunities will you now take advantage of domestically to enhance your intercultural skills after this experience?"

6. "Recalling the Seven Revolutions, which revolution sticks out when visiting some of the sites in Brazil? Why this one? Which event during the trip reminded you of this revolution?"

Debriefing sessions in Brazil were tape recorded, and the audio recordings were transcribed upon return to the U.S. The transcriptions were read through multiple times by the authors and analyzed for reoccurring themes related to the participants' cultural awareness.

Post Education Abroad Reflections. At the end of the Brazil trip, students were asked to reflect on the education abroad experience and how it enhanced the development of their intercultural competence. Students were asked to write short essays addressing the following questions:

1. "Give an example when you experienced the importance of intercultural skills during your visit to Salvador."

2. "Did this trip motivate you to want to continue to develop your intercultural competence? Please state why and share an example(s) that caused this motivation."

3. "Given the above example(s), how will you go about building these skill sets?"

4. "Give an example when you experienced any stress and anxiety around cultural differences during your visit to Salvador. Why did you feel this way? Please share an event that caused this feeling."

5. "If you were sharing your Brazil experience to a peer and you were advocating the need for building intercultural skills, what evidence would you offer advocating education abroad and cultural awareness? Why would you express this specific reason(s)?"

A final question asked participants for any additional responses related to their education abroad experience. Because the questions were identical for both cohorts, we examined the degree to which different themes emerged for the different cohorts.

Data Analysis. For this study, data captured through open-ended questions were analyzed for all recurring themes and pertinent statements taken from the qualitative data 
collected. Ruona's (2005) Constant Comparative Method of Qualitative Data Analysis was primarily used for analyzing qualitative data through the lens of four general stages:

1. Data Preparation: organizing data findings; categories based on important/key findings (cleaning); create filing system.

2. Familiarization: in-depth review of data collected to gain a sense of the information and reflect on its overall meaning.

3. Coding: assigning a label/designation to various aspects of the data to be easily retrieved; placing data into specific categories.

4. Generating Meaning: interpretation of the data; identifying recurring themes/messages.

\section{Findings}

The study's findings are intended to make meaning of the learners' shared experiences. This portion of the narrative will discuss the findings through the use of direct quotes and excerpts from the participants' responses to prompted questions through (a) onsite group debriefings and (b) structured individual reflections at the end of the trip.

\section{Onsite Debriefings During the Education Abroad.}

Transformational learning experiences. Short-term education abroad can provide transformative learning opportunities where learners develop a global perspective, challenge their frames of references and worldviews through use of critical thinking and self-reflection (Smith et al., 2014). The use of critical reflection is encouraged when learners are in situations where they are forced to make a decision in an unfamiliar environment (Jenkins, 2012). Students from both cohorts reflected on the value of cultural immersion and service-learning. When addressing the cultural immersion, students in the second cohort, who lived for a week with a Brazilian family, commented on the impact of the homestays, the relationships that they had made with their families, and even the relationships they had made with the families of other students. Students commented:

"I really enjoyed the home stay. I really liked getting to know Brazil from the Brazilian perspective, I think that's a big piece of this trip that's going to stick with me."

"I didn't think I was going to bond with other people's host families and I did and half of them I know their face but I don't know their name and they know my face and they just come up to me anyway... and it was really cool."

"I think it's so important to do the homestays. Last year's [cohort] didn't do it. Being thrown into a new situation is scary enough, but I've learned so much just sitting in a home, more than I ever thought I would. It was so fun... it was so amazing."

Both cohorts remarked that they had changed in profound ways. Most notably, this was due to the service project, where they worked for several hours (e.g., teaching the children about 
hygiene and physical health, painting a dentist's office, teaching the children some English) in an indigent daycare located in the rural area of Salvador. One student reflected,

"I've never been pushed so far. I've never been exposed to this much poverty. I've never had to walk through a mile of muddy river. Now that my boundaries of my comfort zone have been widened, there's so much more that I can explore so I'm pretty excited."

Another student articulated the transformational nature of the service-learning experience,

"I've gained a new perspective on everything. A new understanding. My understanding of Brazil was so superficial before."

Students echoed these comments noting the experience "empowered" them to help more people and described the learning as "powerful." The quotes illustrate common paradigm shifts experienced by the students as a result of their experience abroad and working collaboratively on a research project with students from another culture.

Cultural differences: Perceptions of other cultures. Dunn postulated that there are few available studies that consider the attitudes and behaviors of local students toward their foreign counterparts (as cited in Collet, 2010, p. 2). The DMIS explains that within the Defense/Reversal orientation there is the state in which one's own culture - or an adopted culture - is superior and other cultures are inferior. The newer version of the IDI (v.3) also includes a separate factor identified as Cultural Disengagement. This portion is not a dimension along the DMIS orientation continuum but is a separate dimension that measures how people relate to their own cultural group and other cultures (Hammer, 2007). Students speak of finding special qualities that are not present in their relationships with friends from a similar cultural background (Collet, 2010). For example, several students commented on differences they saw in valuing relationships and personal connections. They noted that people in Brazil seemed more people-oriented whereas in the U.S., people are less engaging with others and more connected through social media and their electronic devices. Findings convey that students' perceptions of other culture aligned with romanticizing the Brazilian culture and how natives are more engaging and service oriented.

“...people are so open and excited to see us, and even though a lot of us are completely different than they are, they are still excited to learn about us. In America, some people could really care less whether somebody came here."

"I saw that there were people just standing around enjoying each other's company, not necessarily on their phone. We are so into technology... but they kind of have a different value system."

"I found that they really don't care about money and technology as much because they have this wonderful and loving community that they have that we don't really have in the United States." 
Cultural differences: Perceptions of one's own culture. The students' ongoing comparison of their experiences and observations was intriguing and reflected their increasing levels of cross-cultural awareness throughout their time abroad. Several students were relatively critical of U.S. culture, particularly in regards to Americans' reception of visitors and immigrants in comparison to the hospitality they experienced from the Brazilians. This reinforced the notion of students' tendency to romanticize their international experience with the culture while becoming more critical of their own culture. To illustrate this several students remarked, "In America, I think just our mindset is that we are entitled to things..."

"...like back home, we feel that we are entitled to everything, that we deserve it. But down here, they feel that they have to work for it."

"...we are too arrogant to accept that these developing nations actually know what they are doing and we need to learn from them, not the other way around."

Some students recognized their own increasing meta awareness of personal and societal ethnocentric tendencies. One student astutely reflected,

"In America we have big debates on like immigration and stuff and it can be looked down upon when other people don't speak our language but everyone here was so welcoming to us, it kind of opened my eyes to how selfish we can be."

Awareness of sociopolitical issues and their implications. Students were particularly struck by the poverty they witnessed and the degree to which the poverty was so different from what they thought it was like in the U.S. and what they had seen elsewhere in the world:

"These children are coming up to us and they are so grateful for a can of beans and a bag of rice... and then you are walking through their village and their version of a fence is chicken wire with plastic bags tied to it. It makes you re-evaluate where you stand and what you consider 'lower class' and what you consider 'poor."'

"It was interesting to me to see when people understand that they are in poverty. The family [in Brazil] was like, 'Yes, we'd really like a bathroom but we don't have one.'”

Students commented on experiencing guilt as their perceptions of basic needs shifts. For example, one student said, "I had this really incredible guilt," and another commented on how "blessed" most are in the U.S. Their peer echoed these reflections and added that they had previously been likely to judge others before understanding their situation in relation to their own perception and cultural norms.

Cross-cultural communication challenges. Many students noted the challenges in communicating and the language differences - specifically, that Brazilians are more likely than Americans to value learning other languages. It was also noted that Brazilians are more tolerant of people not speaking their primary language (Portuguese) than Americans are when people do not speak their primary language (English). One student observed, 
“Often, when people come to the United States and they're not speaking English we get so offended, but like we come here and we're in the exact same situation, like we don't know what to do and we're scared and so it gave us another perspective."

A peer echoed the sentiment,

"Everyone here spoke some English. We don't even try to learn different languages. I don't know if people think people need to know English, but I feel bad because they are trying and we are not."

These reflections highlight the comparative reflection and shifting beliefs as students integrated new perspectives and experiences.

Racial identity within and across cultures. There were observations around the Brazilians' diversity make up and the recognition by the program's students of color that Brazil's diversity consists of a vast array of one specific race. For these participants, they were surprised by Brazil's large Black population:

"What has stood out for me are the number of Black people. I've seen one or two maybe three white people. One culture is major dominant—one color."

There were obvious comparisons made around the numerous social demographics in the United States versus Brazil's perceived population that consist of only people of color.

"In America it is one big melting pot—you see different races all the time. But here, it takes forever to see anyone of different races, the concentration of one race in one area."

"I just find it really cool how the African culture is really embraced here. I was under the naïve impression that it was only embraced in Africa. It was cool going to the market and seeing all the paintings and I was like, "Black people!" I was just blown away how Blacks are really appreciated in other places in the world. You really don't see that much in America unless you play sports or are a rapper or something like that. They are proud of being Black and it was just so cool to see your culture being appreciated for once."

Although research on the country's population along with other aspects of the country was done prior to the education abroad excursion, becoming fully emerged in the culture and actually experiencing the Brazilian lifestyle created a real-time experience for these specific participants. It also may show why race theories are relevant to the foundation around building intercultural competencies and the influence that the issue of race has on building these skill sets. Critical race theory is a lens allowing for the interrogation of social, educational, and political issues by prioritizing participant voices (Chapman, 2007). There was a larger population of white students who participated in both cohorts. The reluctance to acknowledge differences within a set race 
group could be due to this population of students' collective frame of reference around cultural differences in general.

Reentry Stage: Post Education Abroad Reflections. Students also individually reflected on their experiences on the flight back to the U.S through a post assessment survey. Their open-ended responses were coded in three ways: the positive aspects of the trip, what they found difficult during their visit, and ways they plan to change as a result of this experience.

Positive aspects of the trip. Few differences emerged between the cohorts except with regard to the homestays (mentioned by $27 \%$ of Cohort 2), which was expected given that Cohort 1 did not do homestays. The most commonly mentioned category centered on perceptions of the Brazilian people (e.g., welcoming, open-minded, selfless, people-oriented), which was mentioned by over a quarter of the respondents (28\%). Many students also reported that they thought the trip helped them widen their perspectives and step out of their comfort zone (23\%). Interestingly, $19 \%$ of the sample mentioned their perception that people everywhere are similar in many ways, whereas 17\% noted differences between American and Brazilian cultures.

Twenty percent noted that they enjoyed making a personal connection with a specific person or people in Brazil (outside of the homestay). Nineteen percent mentioned that the undergraduate research experience, particularly being able to talk to their peers while in Brazil, helped change their preconceived notions or stereotypes about Brazil/Brazilians.

Difficulties the students experienced during the trip. The most common theme centered on language barriers - most students knew little or no Portuguese prior to the trip. Language was mentioned overall by $100 \%$ of Cohort 1 and $80 \%$ of Cohort 2 , but there were differences between the cohorts in terms of how they framed the issue. Over two-thirds of Cohort 1 (68\%) specifically mentioned how difficult it was to order food; Cohort 2 was significantly less likely to mention this specific problem (13\%), instead focusing more on communication barriers with their host family (47\%). Also, Cohort $2(33 \%)$ was significantly more likely than Cohort $1(0 \%)$ to mention time issues as a difficulty (e.g., cultural differences surrounding the importance of being on time and reactions to being late). Less commonly, students (12\%) expressed some discomfort with the amount of kissing/hugging that occurred in Brazilian culture.

What students plan to do differently as a result of their experiences abroad. Few significant differences emerged between the cohorts except regarding the importance of interacting with diverse others; this was mentioned by nearly half of Cohort $2(47 \%)$ but only $11 \%$ of Cohort 1 . Popular responses by both cohorts in this category included learning another language (37\%), traveling more (32\%), engaging in personal development, such as becoming more understanding, less judgmental, and more open-minded (27\%), and making a more concerted effort to learn more about other cultures $(26 \%)$. Thirteen percent of the students reported that the experience had prompted them to make a major life change (e.g., change major/minor because of the trip, move to/work in a different country after graduation, join the Peace Corp). 


\section{Discussion}

When preparing undergraduate students for entry into a diverse society and contemporary workforce, developing intercultural competence is a skill set that institutions of higher learning can integrate into their academic curriculum and co-curricular activities. This case study focuses on first-year honors students and their participation in a leadership development program that integrated several interventions aimed at increasing their intercultural competency. Data from individual reflections and group debriefings revealed several key findings. For example, there was a tendency for students to romanticize the Brazilian culture and denigrate their own U.S. culture, and many expressed feelings of guilt about how they have lived their lives and about how much they have relative to others in a developing country (e.g., Ferranto, 2015;

Kartoshkina, 2015; Smith et al., 2014). The students seemed reluctant to say or write anything negative, even though students were exposed to critical information (e.g., widespread corruption in the Brazilian government).

Students in Cohort 2 were very positive overall about their cultural emergence with the Brazilian families in homestays. Unfortunately, Cohort 1 did not do homestays, so this theme did not emerge from them. Research has shown the value of homestays in education abroad experiences; students become immersed in the culture and have the opportunity to form strong relationships with their host family (e.g., Knight \& Schmidt-Rinehart, 2002; Schmidt-Rinehart \& Knight, 2004).

The undergraduate research project helped the students connect with their peers in another country, specifically, the students who attend the university in Salvador, Brazil. There is a need for programs to bring domestic and international students together in meaningful interactions (Deardorff, 2011). It was the intent of this specific intervention to bridge the cohort's learning of cultural awareness through collaborative work with international peers in a partnership to research cultural differences surrounding current global issues as well as enhancing students' intercultural competence by interacting with people with different worldviews. Noticeable statements that reflect the students' perceptions of their work with their international peers and the undergraduate research project included:

When we were talking to the students at UNIFACS [the university in Brazil] and discussing the differences between our data findings, I had to be open and objective and it really allowed for me to understand the true nature of intercultural skills.

Our visit to UNIFACS was very powerful to me because I felt like I learned a lot about Brazil's culture and felt comfortable talking about cultural differences with people my age.

The opportunity to conduct the research and to interact with my Brazilian peers was helpful to my cultural awareness. We realized that we each had stereotypes and assumptions about each other that were not necessarily true. If we all had a better 
understanding of different cultures, we would be able to move past those stereotypes much easier.

Virtually all students felt that their lack of speaking Portuguese was a large communication barrier. However, students in both cohorts framed this issue differently, likely contributing to their very different trip experiences. Most notably, students in Cohort 1 experienced much more structure on their trip; they spent all of their time with their U.S. peers staying in hotels, with a strict itinerary that involved tourism, a service project, authentic Brazilian cuisine, and a visit to a Brazilian ballet. They spent very little time unsupervised without an official translator, and on the few occasions when they ventured off on their own, they did not report much communication or interaction with Brazilian people. The common exception occurred when they ordered food, and many students did not get what they thought they ordered and experienced frustration at not being able to correct their orders. This example again aligns with language barriers challenges.

Cohort 2 had much more unstructured time, both with their U.S. peers as well as with their homestay families and their peers at the host institution. Even though they too had to order food on their own on numerous occasions, they became practiced at navigating through the cultural barriers and were likely much more comfortable by the end of the trip, so much so that this issue did not occur to them to mention in their post-trip reflection essays. Because Cohort 2 was much more immersed in the culture due to the homestays, some cultural differences were much more noticeable to them than to Cohort 1. Specifically, one-third of Cohort 2 mentioned time issues as a difficulty; no one in Cohort 1 mentioned time. Cohort 2 was reliant upon their host families to get to places on time (and get picked up at specified times), so they were much more attuned to this particular cultural difference. Some students had extreme reactions to the different conceptualizations of time in U.S. versus Brazilian cultures; as one student noted:

"In Brazil they are very relaxed about time and do not feel pressured to be on time; whereas, I am a very punctual person and feel very stressed. When my host family was late one morning, I had a panic attack when I got to school [referring to their arrival to the school in Brazil for the day's scheduled sessions]."

Paige (1993) proposes that cultural immersion can create stress and anxiety that leads to frustration, apprehension, tension, culture shock, and in some situations a retreat from wanting to further develop intercultural skills.

Limitations. Although we have rich qualitative data from two cohorts of students in this program, there are some limitations to the data. First, not all students in the program participated in the trip to Brazil, so we are missing their reflections about the program and their thoughts around potential intercultural growth. Second, because the group debriefings that took place in Brazil were semi-structured, the same questions were not asked for both cohorts. Although these variances in protocol are acceptable in an embedded case study design (Yin, 2009), this variance limits the cohort comparisons for this data set in contrast to the comparison we completed for the personal reflection questions, which were the same questions for both cohorts. Third, because 
the program is evolving, several changes were made for Cohort 2 as a result of assessing Cohort 1 's experience. For example, the trip was longer, the students stayed in homes for part of the trip, and the students collaborated with peers in Brazil on their global issues research project. If there are differences in responses across cohort, it is impossible to know which aspect(s) of the program are responsible for those differences.

The literature suggests that short-term programs can have a positive impact on the overall development of cross-cultural sensitivity (Anderson, Lawton, Rexeisen, \& Hubbard, 2006). Assessing the students' responses to programs and interventions to build intercultural dexterity was conducted during a short period of time. In order to determine the long-term effects of being exposed to these learning opportunities that were intentionally put in place for the development of intercultural competence, a longitudinal study should be considered.

Additionally, data findings presented a difficulty in determining which interventions have been most impactful or any understanding of the effectiveness of a specific intervention used by the program leaders. What is shared are the students' attitudes towards their experiences at the end of the academic year, which does not provide an understanding of change over time. Longitudinal studies are essential to the understanding of the effectiveness of international education (Anderson et al., 2006), and this study further demonstrates this need. Consideration of continuing to collect data throughout the program with intent for a longitudinal study will assist in determining if a paradigm shift did actually occur for students who participate in this form of leadership and cultural development.

\section{Implications for Research and Practice}

The purpose of this study was to examine, through qualitative debriefings and written reflections, the extent to which an in-depth program impacted students' intercultural attitudes and behaviors. The results suggest some movement in a positive direction, including interest in learning a new language, increased empathy for individuals who might come to the U.S. as immigrants/visitors who speak little or no English, and heightened awareness of participants' own privileges as relatively affluent U.S. citizens. Students reported intentions to modify their behaviors, awareness and perceptions, for example, travel more, learn more about other cultures, become more open-minded, learn to speak another language, and interact more with diverse others.

Simultaneously, the students appeared to lack a critical reflection lens that would allow them to consider how to effect related social change. For example, many students talked about the extreme poverty that they witnessed in communities abroad, but their reflections centered on how difficult it was to view such poverty and how it made them feel guilty about everything they have. Students did not discuss why they thought there was such extreme poverty, what failings of the government might lead to such conditions, or what could be done to alleviate this poverty, which would have tied nicely with their exposure to the Seven Revolutions and aligned these learned issues from course work with their education abroad experience. However, the students were in their first year of college and perhaps thinking more in-depth about these issues comes 
with time, additional global courses, and more maturity. Overall results of the study remain promising for such student leadership development initiatives. The findings suggest that targeted interventions in the first year of college can have a positive impact on students' levels of intercultural competency and can influence learners to continue to gain cultural awareness, which are critical competencies for leadership development.

This study revealed several implications that can be considered in both the areas of theory and practice. For example, we believe that theoretical intercultural models that are aligned with valid assessment instruments can offer great value when establishing baseline data. Interestingly, undergraduate students frequently overestimate their level of intercultural competence (Sandell \& Tupy, 2015), which makes personal inventories and reflective exercises all the more valuable as instructional tools. Furthermore, these instruments, such as the IDI, can assist instructors in designing and executing appropriate interventions with the intent of building intercultural competence in first-year undergraduate students. The appropriate diagnostic tool should be selected based on the study's purpose, intended outcomes, and target audience. This study also reminds educators to be cognizant of students' various learning levels when exposing them to multicultural education. Specifically, leadership educators can leverage base line measurements to select and develop appropriate cultural awareness activities that meet the learning needs of the audience. This study demonstrates the utility of available inventories for tailoring leadership development curriculum that is targeted for specific skills, such as intercultural competency.

Our experience facilitating the program also revealed the needs for additional curricular elements, such as language training in preparation for education abroad experiences. Furthermore, emerging scholarship suggests the integration of multiple high-impact practices leverages the benefits of each (Bringle, 2017), and our study suggests that students are receptive to such integrated experiences. These findings are helpful for educators and practitioners responsible for leadership development curriculum design and delivery both inside and beyond the formal classroom. 


\section{References}

Anderson, P. H., Lawton, L., Rexeisen, R. J., \& Hubbard, A. C. (2006). Short-term study abroad and intercultural sensitivity: A pilot study. International Journal of Intercultural Relations, 30, 457-469. doi:10.1016/j.ijintrel.2005.10.004

Banks, J. A. (1993). Multicultural education: Historical development, dimensions, and practice. Review of Research in Education, 19, 3-49. Retrieved from http://www.jstor.org/stable/1167339

Belford, N. (2017). International students from Melbourne describing their cross-cultural transitions experiences: Culture shock, social interactions, and friendship development. Journal of International Students, 7(3), 499-527. doi: 10.5281/zenodo.569941

Bennett, M. J. (1986). A developmental approach to training for intercultural sensitivity. International Journal of Intercultural Relations, 10(2), 179-195. doi:10.1016/01471767(86)90005-2

Bennett, M. J. (Ed.) (1998). Basic concepts of intercultural communications. Boston, MA: Nicholas Brealey Publishing.

Bennett, M. J. (2009). Defining, measuring, and facilitating learning: A conceptual introduction to the intercultural education double supplement. Supplement 1 on 'State of the art research on intercultural learning in study abroad' and Supplement 2 on 'Best practice for intercultural learning in international educational exchange.' Intercultural Education, 20(S1-2), S1-13. doi: 10.1080/14675980903370763

Bentley, R., \& Ellison, K. J. (2007). Increasing cultural competence in nursing through international service-learning experiences. Nurse Educator, 32(5), 207-211. doi: 10.1097/01.NNE.0000289385.14007.b4

Braskamp, L. A., \& Engberg, M. E. (2011). How colleges can enhance global perspective taking. Liberal Education, 97(3/4), 34-39.

Bringle, R. (2017). Hybrid high-impact practies: Integrating service-learning with other high impact practices. International Association for Research on Service-Learning and Community Engagement. NUI Galway, Ireland.

Center for Strategic and International Studies (2015). Seven Revolutions. Retrieved from http://csis.org/program/seven-revolutions 
Caffrey, R. A., Neander, W., Markle, D., \& Stewart, B. (2005). Improving the cultural competence of nursing students: Results of integrating cultural content in the curriculum and an international immersion experience. Journal of Nursing Education, 44(5), 234240.

Chapman, T. K. (2007). Interrogating classroom relationships and events: Using portraiture and critical race theory in education research. Educational Researcher, 36(3), 156-162. https://doi.org/10.3102/0013189X07301437

Collett, D. (2010). Interaction between local and international students using inclusive approaches to intercultural dialogue. $21^{\text {st }}$ ISANA International Education Association Conference Proceedings. The Gap, Queensland, Australia. Retrieved from http://isana.proceedings.com.au/2010-conference

Council on Undergraduate Research. (n.d.). Fact sheet. Retrieved from http://www.cur.org/about_cur/fact_sheet/

Deardorff, D. K. (Spring, 2011). Assessing intercultural competence. New Directions for Institutional Research, 149, 65-79. doi:10.1002/ir.381

Devine, J. J., Green, C., \& McDowell, S. (2010). The global pathways initiative: Florida State University's interdisciplinary efforts to become interculturally competent. Making Connections: Interdisciplinary Approaches to Cultural Diversity, 11(2), 1-13.

Eldaba, A. (2016). An innovative model to design an academic and social development program for international college students. College Student Journal, 50(2), 171-178.

Ferranto, M. L. G. (2015). A qualitative study of baccalaureate nursing students following an eight-day international cultural experience in Tanzania: Cultural humility as an outcome. Procedia - Social and Behavioral Sciences, 174, 91-102. https://doi.org/10.1016/j.sbspro.2015.01.631

Ganz, M., \& Lin, E. (2011). Learning to lead: Pedagogy of practice. In S. Snook, N. Nohria, \& R. Khurana (Eds.), Handbook for teaching leadership: Knowing, doing, and being (pp. 353-366). Los Angeles: Sage.

Haber-Curran, P., \& Owen, J. E. (2013). Engaging the whole student: Student affairs and the national leadership education research agenda. Journal of Leadership Education, 12(3), 38-50. doi: 10.12806/V12/I3/TF2

Hammer, M. R. (2007). The Intercultural Development Inventory manual (Vol. 3). Ocean Pines, MD: IDI, LLC. Reviewed by: Jingzhu Zhang, College of William and Mary, Williamsburg, VA, USA doi: 10.1177/0734282913505075 
Hammer, M. R., Bennett, M. J., \& Wiseman, R. (2003). Measuring intercultural sensitivity: The Intercultural Development Inventory. International Journal of Intercultural Relations, 27, 421-443. https://doi.org/10.1016/S0147-1767(03)00032-4

Jackson, J. (2015). Becoming interculturally competent: Theory to practice in international education. International Journal of Intercultural Relations, 48, 91-107. https://doi.org/10.1016/j.ijintrel.2015.03.012

Jenkins, D. M. (2012). Global critical leadership: Educating global leaders with critical leadership competencies. Journal of Leadership Studies, 6(2), 95-101. doi: $10.1002 / \mathrm{jls} .21241$

Jenkins, D. M. (2013). Exploring instructional strategies in student leadership development programming. Journal of Leadership Studies, 6, 48-62. doi: $10.1002 /$ jls.21266

Kartoshkina, Y. (2015). Bitter-sweet reentry after studying abroad. International Journal of Intercultural Relations, 44, 35-45. doi: 10.1016/j.ijintrel.2014.11.001

Knight, S. M., \& Schmidt-Rinehart, B. C. (2002). Enhancing the homestay: Study abroad from the host family perspective. Foreign Language Annals, 35(2), 190-201.

Kolb, D. A. (1983). Experiential learning: Experience as the source of learning and development. Englewood Cliffs, NJ: Prentice Hall.

Komives, S. R., Dugan, J. P., Owen, J. E., Slack, C., \& Wagner, W. (Eds). (2006). Handbook for student leadership programs. College Park, MD: National Clearinghouse for Leadership Programs.

Kuh, G. D. (2008). High-impact educational practices: What they are, who has access to them, and why they matter. Washington, DC: Association of American Colleges and Universities.

Lincoln, Y. S. \& Guba, E. G. (1985). Naturalistic inquiry. Newbury Park, CA: Sage.

Mahoney, L. J., \& Cairns, B. R. (1997). Do extracurricular activities protect against early school dropout? Developmental Psychology, 33(2), 241-253. http://dx.doi.org/10.1037/00121649.33.2.241

Mezirow, J. (1994). Transformative dimensions of adult learning. San Francisco: Jossey Bass.

Mezirow, J. (2000). Learning as transformation: Critical perspectives on a theory in progress. San Francisco: Jossey Bass. 
Miller-Perrin, C., \& Thompson, D. (2014). Outcomes of global education: External and internal change associated with study abroad. New Directions for Student Services, 146, 77-89. doi: $10.1002 /$ ss.20093

Miles, D. H. (2003). The 30-second encyclopedia of learning and performance: A trainer's guide to theory, terminology, and practice. New York: American Management Association.

Morris, P. V., \& McClure, M. D. (2011). The assessment of changes in intercultural sensitivity among undergrad students in the college of agriculture: Measurement over three semesters. The International Journal of Diversity in Organisations, Communities, and Nations, 10(6), 169-181.

Niehaus, E. K., O'Rourke, M. A., \& Ostick, D. T. (2012). Global leadership development plans: Engaging students as agents in their own development. Journal of Leadership Studies, 6(2), 116-122. doi:10.1002/jls.21244

Olson, J. E., \& Lalley, K. (2012). Evaluating a short-term, first-year study abroad program for business and engineering undergraduates: Understanding the student learning experience. Journal of Education for Business, 87, 325-332. http://dx.doi.org/10.1080/08832323.2011.627889

Owen, J. E. (2015). Transforming leadership development for significant learning. New Directions for Student Leadership, 145, 7-17. doi:10.1002/yd.20120

Paige, R. M. (1993). On the nature of intercultural experiences and intercultural education. In R. M. Paige (Ed.), Education for the intercultural experience (pp. 1-20). Yarmouth, ME: Intercultural Press, Inc.

Paterson, G., Rachfall, T., \& Reid, C. (2013). Building a culture of research: Using undergraduate research to advance the TR profession, build research capacity, and foster collaborative relationships. Therapeutic Recreation Journal, 47(4), 259-275. Retrieved from http://js.sagamorepub.com/trj/article/view/4534

Ruona, W. E. (2005). Analyzing qualitative data. In R.A. Swanson \& E. F. Holton (Eds.), Research in organizations: Foundations and methods of inquiry (pp. 223-263). San Francisco, CA: Berrett-Koehler.

Sandell, E. J., \& Tupy, S. J. (2015). Where cultural competency begins: Changes in undergraduate students' intercultural competency. International Journal of Teaching \& Learning in Higher Education, 27(3), 364-381. Retrieved from http://www.isetl.org/ijtlhe/current.cfm.

Schmidt-Rinehart, B. C., \& Knight, S. M. (2004). The homestay component of study abroad: Three perspectives. Foreign Language Annals, 37(2), 254-262. 
Seemiller, C. (2013). The student leadership competencies guidebook: Designing intentional leadership learning and development. San Francisco: Jossey-Bass.

Smith, J. E., McAuliffe, G., \& Rippard, K. S. (2014). Counseling students' transformative learning through a study abroad curriculum. Counselor Education \& Supervision, 53, 306-319.

Soria, K. M., \& Troisi, J. (2014). Internationalization at home alternatives to study abroad: Implications for students' development of global, international, and intercultural competencies. Journal of Studies in International Education, 18, 261-280. doi: $10.1177 / 1028315313496572$

Sowcik, M., Andenoro, A., McNutt, M., \& Murphy, S. (Eds.) (2015). Leadership 2050, Critical Challenges, Key Contexts and Emerging Trends. (1st ed.) (Building Leadership Bridges). UK: Emerald Group Publishing Limited.

Walling, S. M., Eriksson, C. B., Meese, K. J., Ciovica, A., Gorton, D., \& Foy, D. W. (2006). Cultural identity and reentry in short-term student missionaries. Journal of Psychology and Theology, 34(2), 153-164.

Wells, M. I. (2000). Beyond cultural competence: A model for individual and institutional cultural development. Journal of Community Health Nursing, 17, 189-199. doi: 10.1207/S15327655JCHN1704_1

Wilson, A. B. (2015). Examining the role of multicultural competence in leadership program design. Journal of Leadership Studies, 14(1), 1-13.

Yin, R. K. (2009). Case study research: Design and methods $\left(4^{\text {th }}\right.$ ed.). Thousand Oaks, CA: Sage Publications, Inc. Retrieved from http://trove.nla.gov.au/version/184922167

Zimmerman, J. (2015). Lessons from abroad: Teaching cultural and global leadership in the U.S. classroom. Journal of Leadership Studies, Special 2015, 114-125. doi: 1012806/V14/I4/A2 


\section{Author Biographies}

Linda M. Lyons, Ed.D. (llyons@ @ennesaw.edu) managers the strategic planning process for her college and teaches leadership development courses that are germane to diversity and inclusion as well as multicultural education. Her research focus explores how learners build intercultural competence through their participation of global learning curricular and education abroad experiences.

Amy M. Buddie, Ph.D. (abuddie@ kennesaw.edu) is the Director of the Office of Undergraduate Research and a Professor of Psychology at Kennesaw State University. She works with students and faculty to promote undergraduate research/creative activity on her campus. Her current research examines perceived benefits of and barriers to undergraduate research.

Jennifer W. Purcell, Ed.D. (jwpurcell@kennesaw.edu) is an assistant professor the Department of Leadership and Integrative Studies and member of the graduate faculty at Kennesaw State University. Her research explores learning, leadership, and organization development with emphasis on partnerships, collaboration, and institutional change. 